\title{
GMR
}

\section{Proteomic analysis of mycelial proteins from Magnaporthe oryzae under nitrogen starvation}

\author{
X.-G. Zhou ${ }^{1,2}$, P. Yu ${ }^{2}$ C. Dong ${ }^{2}$, C.-X. Yao², Y.-M. Ding ${ }^{2}$, N. Tao ${ }^{2}$ and \\ Z.-W. Zhao ${ }^{1}$
}

${ }^{1}$ State Key Laboratory for Conservation and Utilization of Bio-Resources in Yunnan, Yunnan University, Kunming, China

${ }^{2}$ Key Laboratory of Southwestern Crop Gene Resources and Germplasm Innovation, Ministry of Agriculture and Yunnan Provincial Key Laboratory of Agricultural Biotechnology, Biotechnology and Germplasm Resources Institute, Yunnan Academy of Agricultural Sciences, Kunming, China

Corresponding author: Z.W. Zhao

E-mail: zhaozhw@ynu.edu.cn

Genet. Mol. Res. 15 (2): gmr.15028637

Received March 23, 2016

Accepted April 11, 2016

Published May 13, 2016

DOI http://dx.doi.org/10.4238/gmr.15028637

\begin{abstract}
Magnaporthe oryzae is an important model system in studies of plant pathogenic fungi, and nitrogen is a key nutrient source affecting microbial growth and development. In order to understand how nitrogen stress causes changes in mycelial proteins, we analyzed differentially expressed mycelial proteins from the $M$. oryzae virulent strain $\mathrm{CH}-63$ using two-dimensional electrophoresis and mass spectrometry in complete medium or under nitrogen starvation conditions. A total of $975 \pm 70$ and $1169 \pm 90$ protein spots were detected in complete medium and under nitrogen starvation conditions, respectively. Forty-nine protein spots exhibited at least 2-fold upregulation or down-regulation at the protein level according to PDQuest7.4. Moreover, 43 protein spots were successfully identified by matrix-assisted laser desorption/ionization-time-of-flight/time-of-flight mass spectrometry. Among these spots, 6 proteins were functionally unknown and 37 proteins were categorized into 5 groups according to
\end{abstract}


their functions, including development, metabolism, biosynthesis, and biological process. These 37 proteins were further analyzed for their enriched metabolic pathways by KOBAS2.0, and 14 proteins were found to be involved in glycolysis, tricarboxylic acid cycle, and nitrogen metabolism. Taken together, the regulation of M. oryzae growth under the nitrogen starvation conditions appears to be complex because of the various proteins and enzymes involved.

Key words: Mass spectrometry; Mycelium; Nitrogen stress; Proteome; Rice blast fungus

\section{INTRODUCTION}

Rice (Oryza sativa) is a major crop that feeds millions of people worldwide, particularly in Asia and Africa (Talbot, 2003). Cultivated rice is exposed to numerous abiotic and biotic stresses (Mahajan and Tuteja, 2005). Rice blast disease caused by Magnaporthe oryzae is the most devastating disease in rice-growing regions worldwide (Liu et al., 2010). The control of rice blast depends on breeding resistant cultivars and applying chemical fungicides. However, it is important to understand the mechanisms of pathogenesis and host resistance to control fungal infection. Therefore, the molecular characterization of $M$. oryzae may reveal effective strategies for preventing various plant diseases. To evaluate the interactions between rice plants and M. oryzae on the molecular, biochemical, and physiological levels, high-throughput technologies such as transcriptomics, proteomics, and metabolomics have been used (Agrawal and Rakwal, 2011; Mathioni et al., 2011; Jones et al., 2011).

Nitrogen is an important nutrient source for microbial growth and development. Stress caused by a lack of nitrogen source is one of the major environmental stresses for $M$. oryzae in rice. Nitrogen deficiency can induce M. oryzae to secret pathogenic proteins (Wang et al., 2011) and protoplast-disrupting proteins (Rathour et al., 2003).

Proteomics technology can be used to rapidly analyze proteins from different individuals, organizations, and growth periods. In particular, two-dimensional electrophoresis (2-DE) has become an important research tool. Recently, a variety of plant pathogenic fungi has been investigated through proteomics (Garg et al., 2002). The pathogenesis of most of these fungi has been explored based on secreted proteins (Fernández-Acero et al., 2010), mycelia (Bregar et al., 2012), and conidia (Noir et al., 2009).

Proteomics studies for M. oryzae have been conducted on secreted proteins (Wang et al., 2011) and conidia (Bhadauria et al., 2010), but not on mycelium. However, secreted proteins, all from hyphae, are the main factors causing rice blast. Therefore, it is important to characterize $M$. oryzae mycelium using proteomics in order to understand the pathogenic mechanism.

\section{MATERIAL AND METHODS}

\section{Materials}

\section{Strains and media}

Magnaporthe oryzae CH-63 was kindly provided by Chengyun Li from Yunnan 
Agricultural University, China. The following culture media were used in this study:

1) Solid medium: $15.0 \mathrm{~g}$ glucose, $5.0 \mathrm{~g}$ yeast extract, and $12.0 \mathrm{~g}$ agar in $1.0 \mathrm{~L} \mathrm{H}_{2} \mathrm{O}$.

2) Trace elements: $2.20 \mathrm{~g} \mathrm{ZnSO}_{4} \cdot 7 \mathrm{H}_{2} \mathrm{O}, 10 \mathrm{~g} \mathrm{H}_{3} \mathrm{BO}_{3}, 0.50 \mathrm{~g} \mathrm{MnCl} \cdot 4 \mathrm{H}_{2} \mathrm{O}, 0.50 \mathrm{~g}$

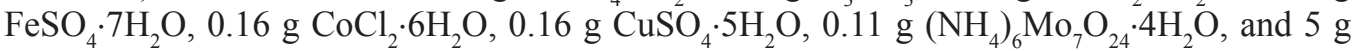
$\mathrm{Na}_{2}$-EDTA in $1.0 \mathrm{~L} \mathrm{H}_{2} \mathrm{O}$.

3) Liquid complete medium (CM): $6 \mathrm{~g} \mathrm{NaNO}_{3}, 0.52 \mathrm{~g} \mathrm{KCl}, 0.52 \mathrm{~g} \mathrm{MgSO}_{4} \cdot 7 \mathrm{H}_{2} \mathrm{O}, 1.52 \mathrm{~g}$ $\mathrm{KH}_{2} \mathrm{PO}_{4}, 10 \mathrm{~g}$ glucose, $2 \mathrm{~mL}$ trace elements, $2 \mathrm{~g}$ peptone, $1 \mathrm{~g}$ yeast extract, and $1 \mathrm{~g}$ casein in $1.0 \mathrm{~L} \mathrm{H}_{2} \mathrm{O}$.

4) $\mathrm{N}$ starvation complete medium (CM-N): $0.52 \mathrm{~g} \mathrm{KCl}, 0.52 \mathrm{~g} \mathrm{Mg}_{2} \mathrm{SO}_{4} \cdot 7 \mathrm{H}_{2} \mathrm{O}, 1.52 \mathrm{~g}$ $\mathrm{KH}_{2} \mathrm{PO}_{4}, 10$ g glucose, and $2 \mathrm{~mL}$ trace elements in $1.0 \mathrm{~L} \mathrm{H}_{2} \mathrm{O}$.

\section{Strain culture and mycelium preparation}

Strains of $M$. oryzae were grown on solid medium at $28^{\circ} \mathrm{C}$ for 7 days in the dark. Three $0.5 \times 0.5-\mathrm{cm}$ plugs of mycelia were added to $50 \mathrm{~mL} \mathrm{CM}$ and incubated at $28^{\circ} \mathrm{C}$ and 150 rpm for 3 days. Cultures were filtered and rinsed with sterile water. A part of the mycelia was moved to $50 \mathrm{~mL} \mathrm{CM}$, while another part was moved to $50 \mathrm{~mL} \mathrm{CM}-\mathrm{N}$. These samples were incubated at $28^{\circ} \mathrm{C}$ and $150 \mathrm{rpm}$ for 2 days. Finally, the mycelia were filtered and rinsed.

\section{Methods}

\section{Mycelial protein extraction}

Briefly, $1 \mathrm{~g}$ of mycelia was ground to a fine powder in liquid nitrogen and suspended in $30 \mathrm{~mL}$ acetone containing 10\% trichloroacetic acid, $0.1 \%$ dithiothreitol (DTT) and $1 \%$ phenylmethanesulfonyl fluoride. The mycelium suspension was incubated at $-20^{\circ} \mathrm{C}$ overnight and centrifuged at $10,000 \mathrm{~g}$ for $10 \mathrm{~min}$. The precipitate was washed with $30 \mathrm{~mL} 80 \%$ acetone 3 times, incubated at $-20^{\circ} \mathrm{C}$ for $2 \mathrm{~h}$, centrifuged at $10,000 \mathrm{~g}$ for $10 \mathrm{~min}$, and then vacuumdried. Crude mycelial protein was dissolved in rehydration buffer (7 M urea, $2 \mathrm{M}$ thiourea, $4 \%$ CHAPS, $65 \mathrm{mM}$ DTT, 0.2\% IPG buffer, $0.001 \%$ bromophenol blue) at a ratio of $1: 15$ (mg: $\mu \mathrm{L})$. Protein solution was incubated at room temperature for $1 \mathrm{~h}$ and then centrifuged at $10,000 \mathrm{~g}$ for $10 \mathrm{~min}$. The obtained supernatant was precipitated by the addition of 4 volumes of ice-cold acetone containing $1 \%$ DTT at $-20^{\circ} \mathrm{C}$ for $2 \mathrm{~h}$. The pellet was dissolved in rehydration buffer. Protein concentration was determined using the Bradford method (Bradford, 1976).

\section{2-DE and image analysis}

Within a $\mathrm{pH}$ range of 4-7, 24-cm immobilized $\mathrm{pH}$ gradient (IPG) strips (GE Healthcare, Little Chalfont, UK) were hydrated according to the manufacturer instructions. Briefly, 600 $\mathrm{mg}$ total proteins were dissolved in $500 \mu \mathrm{L}$ rehydration buffer. Isoelectric focusing was conducted using an IPGphor II (GE Healthcare) according to the manufacturer instructions under the following conditions: $250 \mathrm{~V}$ for $30 \mathrm{~min}, 500 \mathrm{~V}$ for $30 \mathrm{~min}, 1000 \mathrm{~V}$ for $30 \mathrm{~min}, 8000$ $\mathrm{V}$ for $4 \mathrm{~h}$, and $8000 \mathrm{~V}$ for $75,000 \mathrm{Vh}$. The strips were then sequentially placed in equilibration buffer-1 (6 M urea, 2\% sodium dodecyl sulfate, $50 \mathrm{mM}$ Tris- $\mathrm{HCl} \mathrm{pH} \mathrm{8.8,20 \%} \mathrm{glycerol,} \mathrm{2 \%}$ DTT) and equilibration buffer-2 (6 M urea, $2 \%$ sodium dodecyl sulfate, $50 \mathrm{mM}$ Tris- $\mathrm{HCl}$, $20 \%$ glycerol, $2.5 \%$ iodoacetamide) for $15 \mathrm{~min}$, respectively. The equilibrated strips were run in a Ettan DAL Tsix (GE Healthcare) using 12\% sodium dodecyl sulfate-polyacrylamide 
gel electrophoresis at $10 \mathrm{~mA} / \mathrm{gel}$ for $30 \mathrm{~min}$, and then $30 \mathrm{~mA} / \mathrm{gel}$ until the bromophenol blue reached the bottom of the gel. The gels were stained by Coomassie Brilliant Blue G-250, scanned using a UMAX Power Look scanner at a resolution of 300 dpi in gray scale mode, and then analyzed using PDQuest 7.4 (Bio-Rad, Hercules, CA, USA). A total of six maps, including three replicate maps, were analyzed. Spots were detected, matched, and normalized based on total density in the gel image according to the software guide. Isoelectric point and molecular weight $(\mathrm{Mr})$ values were calculated according to the IEF strips range and protein standard markers, respectively. To create a statistical analysis set, the Student $t$-test was performed at a significance level of $95 \%$.

\section{Mass spectrometry and database searching}

The intensity of each spot was measured in three biological replicates. Protein spots with an expression fold difference of $>2$ were selected for further identiðcation. Digging and mass spectrometry were performed on these protein spots. Trypsin digestion and 4800 Proteomics Analyzer MALDI-TOF/TOF of ABI (Applied Biosystems, Foster City, CA, USA) were performed as described previously (Yu et al., 2015). Protein sequences meeting the requirements were functionally classified through metabolic pathway analysis based on Gene Ontology (http:// www.geneontology.org/) and KOBAS2.0 (http://kobas.cbi.pku.edu.cn/home.do).

\section{RESULTS}

\section{2-DE imaging for mycelial protein}

Figure 1 shows the 2-DE image of mycelial proteins from M. oryzae $\mathrm{CH}-63$ cultured in $\mathrm{CM}$ and CM-N. The image shows a light background, good dyeing effect, clear separation of protein points, and no significant horizontal or vertical tails. Protein spots were distributed throughout the 24-cm IPG strips and a 12\% gel. Experiments were performed in triplicate, and the 2-DE maps were analyzed using PDQuest 7.4 (Bio-Rad). A total of $975 \pm 70$ and $1169 \pm 90$ protein spots were detected in $\mathrm{CM}$ and $\mathrm{CM}-\mathrm{N}$, respectively. Our results revealed that nitrogen starvation induced the expression of additional proteins. Figure 2 shows enlarged pictures of the 43 proteins.

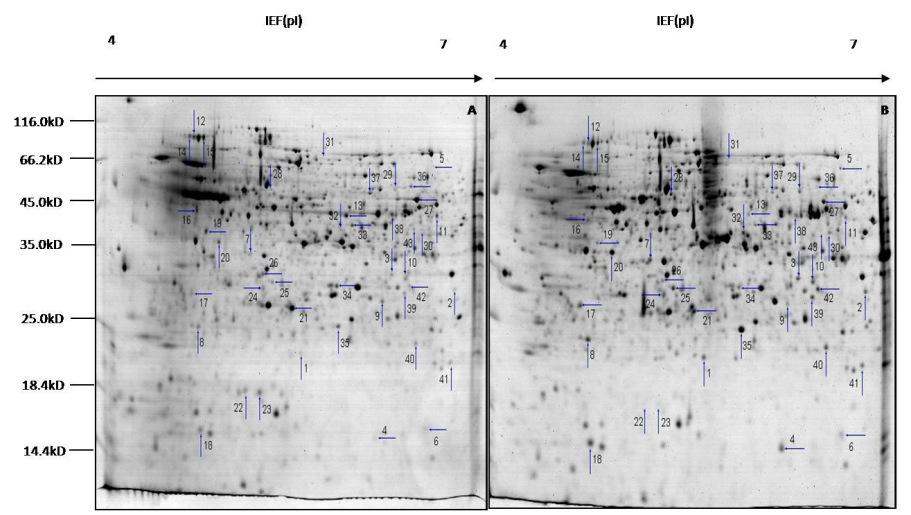

Figure 1. 2-DE maps of mycelial proteins cultivated in CM and CM-N from Magnaporthe oryzae. A. M. oryzae cultivated in CM. B. M. oryzae cultivated in CM-N. 


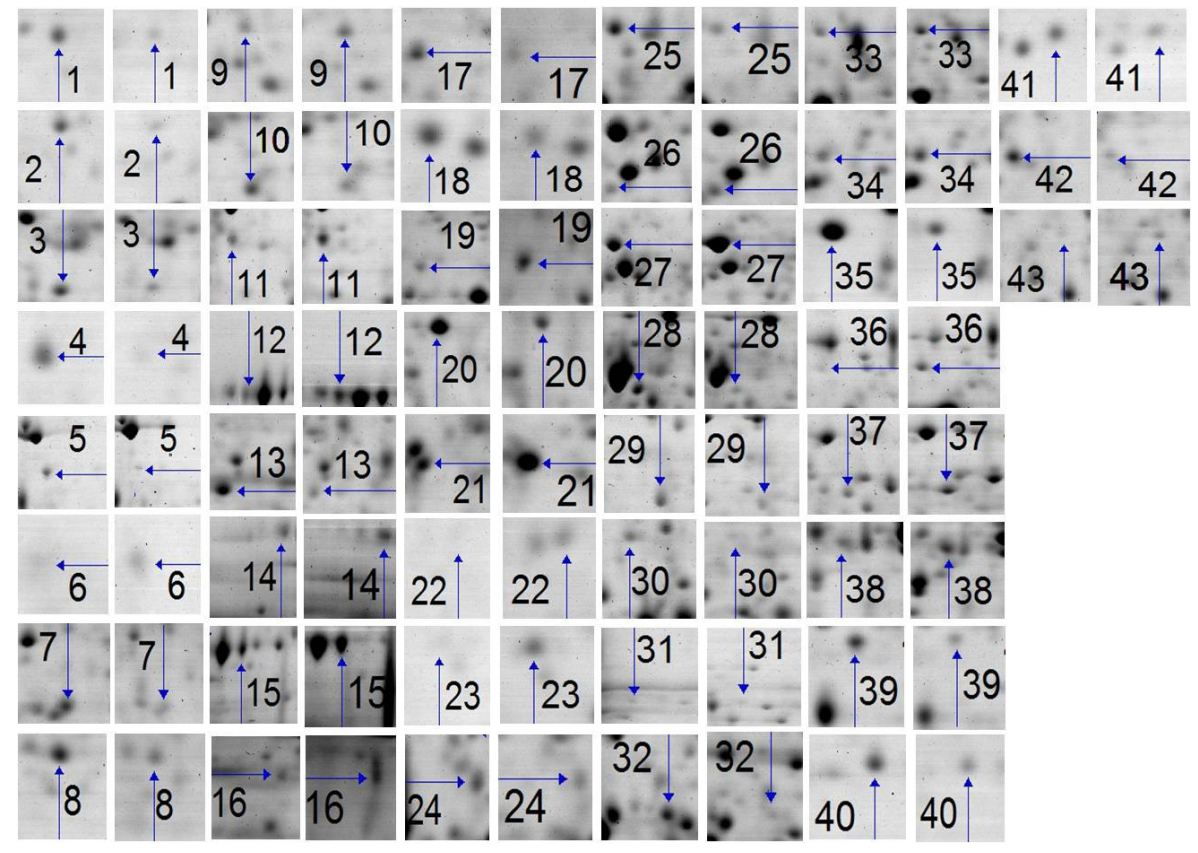

Figure 2. Enlarged pictures of differently expressed proteins.

\section{Protein expression and mass spectrometry analysis}

Compared with samples cultured under CM conditions, 49 protein spots showed a $>2$-fold change at the protein level. These differentially expressed proteins were analyzed by matrix-assisted laser desorption/ionization-time-of-flight-mass spectrometry (MS)/MS. Fortythree proteins were successfully identified, and the remaining 6 proteins were considered as failures. Table 1 shows the preliminary identification of 43 protein spots, including 23 upregulated and 20 down-regulated proteins. Identified proteins were functionally classified into 5 known categories and 1 unknown group: development (23.3\%), metabolism (41.9\%), translation (2.3\%), transport (2.3\%), cellular component (16.3\%), and unknown function (14\%).

\section{KEGG analysis}

Among the 43 proteins, spots 29 spots 33 were the same proteins elongation factor 1 -gamma. Spots 7 , spots 14 , spots 15 were the same proteins trehalase precursor. Thus, 40 proteins were analyzed by KEGG. However, only 24 proteins were categorized into metabolic pathways by KEGG (Table 2). We found that 8 proteins were involved in carbon metabolism and 12 proteins in glycometabolism (Figure 3A), amino acid metabolism (Figure 3B), and nitrogen metabolism (Figure 3C). In addition, spots 10, 19, and 28 were involved in oxidative phosphorylation; spot 16 was involved in protein processing in the endoplasmic reticulum; spot 21 was involved in cell cycling; spot 41 was involved in the proteasome; spot 12 was involved in the phagosome; spots 3 and 30 were involved in butanoate metabolism; and spot 36 was involved in tyrosine metabolism. Furthermore, 3 up-regulated proteins (trehalase, 
glucose-6-phosphate isomerase, phosphoglycerate kinase) and 3 down-regulated proteins (transaldolase, aldose reductase, enolase) were involved in glycometabolism. Thus, M. oryzae $\mathrm{CH}-63$ responded to nitrogen starvation by regulating carbon metabolism.

Table 1. Differentially expressed mycelial proteins in Magnaporthe oryzae cultivated with CM and CM-N.

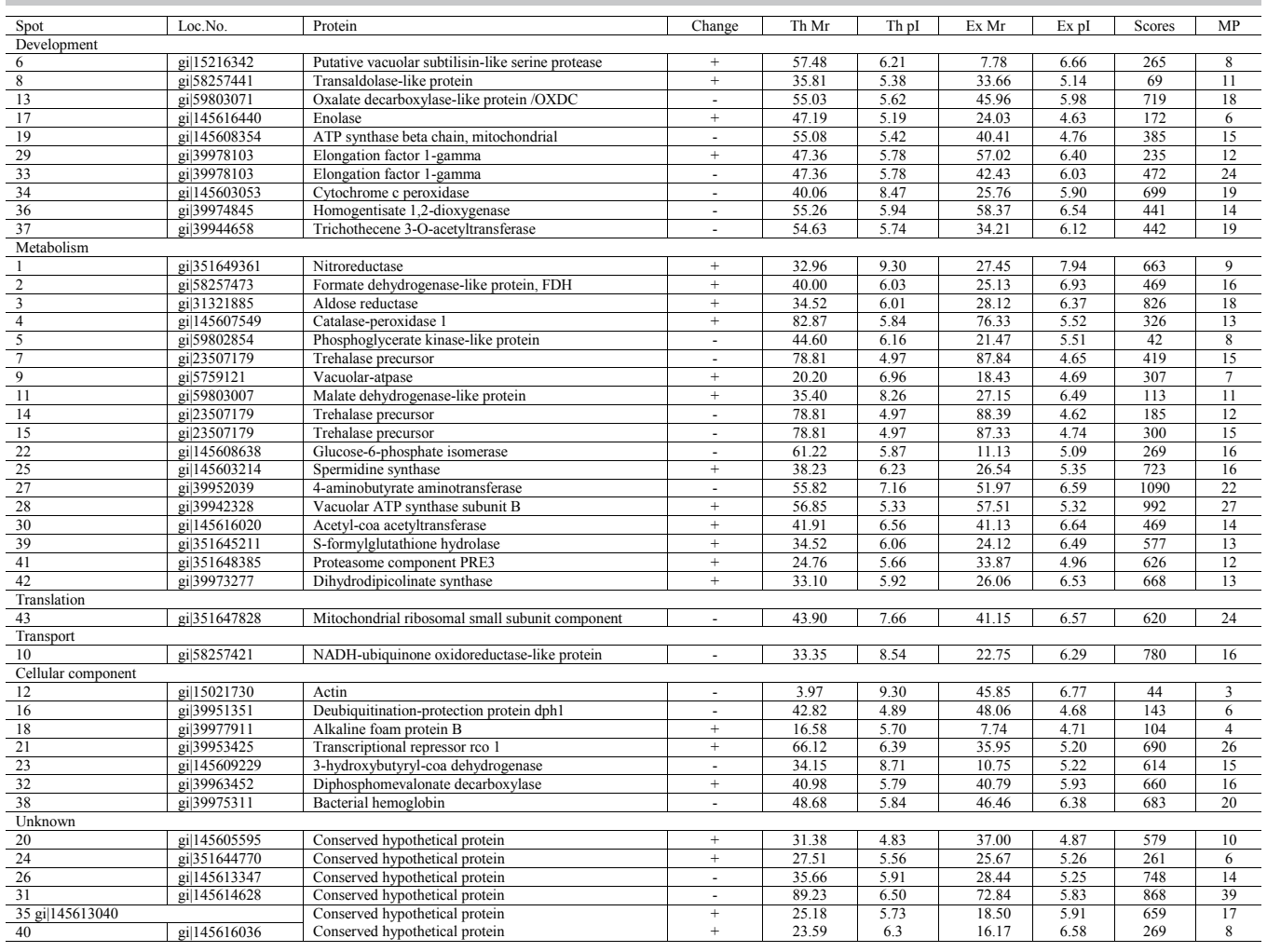

Loc. No., locus number; MP, number of matched peptides; Ex Mr, experimental molecular weight; $\mathrm{Th} \mathrm{Mr}$, theoretical molecular weight; Ex pI, experimental isoelectric point; Th pI, theoretical isoelectric point; +, upregulated proteins; -, downregulated proteins.

\section{DISCUSSION}

As the key enzyme in the catabolic process of trehalose, trehalase directly affects trehalose content. Trehalose stores carbohydrates not only to cope with carbon starvation, but also in response to abiotic stress, such as salt and high temperature (Garg et al., 2002; Cortina and Culiáñez-Macià, 2005; Salmerón-Santiago et al., 2011). Our data showed that in response to nitrogen starvation, $M$. oryzae reduced the expression levels of trehalase in order to increase trehalose accumulation to enhance resistance. Fructose-6P synthesis is blocked from glucose-6P by glucose-6-phosphate isomerase, while it is promoted by other pathways involving transaldolase and aldose reductase. In addition, transaldolase plays a key role in a variety of life activities, development, and metabolism. Gene expression levels increase during the early stage of $M$. oryzae infestation. Aldose reductase, in the presence of NADH, 


\begin{tabular}{|c|c|c|c|c|c|}
\hline Term & ID & Input number & Background number & P value & Input \\
\hline Carbon metabolism & mgr01200 & 8 & 99 & 0.002239875 & $|11| 39|17| 22|30| 2|5| 8$ \\
\hline Butanoate metabolism & mgr00650 & 3 & 22 & 0.016811924 & $30|27| 23$ \\
\hline Glyoxylate and dicarboxylate metabolism & mgr00630 & 3 & 23 & 0.018706966 & $11|2| 30$ \\
\hline Methane metabolism & mgr00680 & 3 & 25 & 0.022838937 & \begin{tabular}{|l|l|}
$39|2| 17$ \\
\end{tabular} \\
\hline Glycolysis / Gluconeogenesis & mgro0010 & 3 & 39 & 0.064298189 & $5|17| 22$ \\
\hline Propanoate metabolism & mgr00640 & 2 & 17 & 0.064561199 & $27 \mid 30$ \\
\hline Terpenoid backbone biosynthesis & mgro0900 & 2 & 18 & 0.070732466 & $32 \mid 30$ \\
\hline beta-Alanine metabolism & mgr00410 & 2 & 18 & 0.070732466 & $25 \mid 27$ \\
\hline Phenylalanine metabolism & $\mathrm{mgr} 00360$ & 2 & 20 & 0.08361611 & $4 / 23$ \\
\hline Pentose phosphate pathway & mgro0030 & 2 & 23 & 0.104136343 & $8 \mid 22$ \\
\hline Synthesis and degradation of ketone bodies & $\mathrm{mgr} 00072$ & 1 & 5 & 0.125358225 & 30 \\
\hline Tryptophan metabolism & mgro0380 & 2 & 26 & 0.125857062 & $30 \mid 4$ \\
\hline Valine, leucine and isoleucine degradation & mgr00280 & 2 & 29 & 0.148540925 & $27 / 30$ \\
\hline Pyruvate metabolism & mgro0620 & 2 & 33 & 0.17992082 & $11 \mid 30$ \\
\hline Phagosome & mgr04145 & 2 & 36 & 0.204065975 & $12 \mid 28$ \\
\hline Cysteine and methionine metabolism & mgr00270 & 2 & 38 & 0.220361583 & $11 \mid 25$ \\
\hline Oxidative phosphorylation & mgr00190 & 3 & 73 & 0.234802078 & $19|10| 28$ \\
\hline Starch and sucrose metabolism & mgr00500 & 2 & 40 & 0.236765163 & $7 \mid 22$ \\
\hline Fatty acid degradation & mgro0071 & 1 & 18 & 0.346125281 & 30 \\
\hline Lysine degradation & $\mathrm{mgr} 00310$ & 1 & 18 & 0.346125281 & 30 \\
\hline Metabolic pathways & mgro1100 & 18 & 734 & 0.391343851 & $|11| 25|27| 17|22| 23|19| 32|30| 28|36| 3|2| 5|4| 7|8| 10$ \\
\hline Glutathione metabolism & mgr00480 & 1 & 22 & 0.402223541 & 25 \\
\hline Fatty acid metabolism & mgr01212 & 1 & 24 & 0.42846056 & 30 \\
\hline Citrate cycle (TCA cycle) & mgro0020 & 1 & 26 & 0.453558385 & \\
\hline Glycerolipid metabolism & mgro0561 & 1 & 27 & 0.465695471 & 3 \\
\hline Tyrosine metabolism & mgr00350 & 1 & 27 & 0.465695471 & 36 \\
\hline Alanine, aspartate and glutamate metabolism & $\mathrm{mgr} 00250$ & 1 & 27 & 0.465695471 & 27 \\
\hline Biosynthesis of amino acids & mgro1230 & 3 & 116 & 0.491958538 & $8|5| 17$ \\
\hline Biosynthesis of secondary metabolites & mgr01110 & 7 & 295 & 0.504013509 & \begin{tabular}{|l|l|}
$11|22| 17|32| 30|5| 8$ \\
\end{tabular} \\
\hline Proteasome & mgr03050 & 1 & 34 & 0.543505597 & 41 \\
\hline Arginine and proline metabolism & mgr00330 & 1 & 36 & 0.563601056 & 25 \\
\hline Amino sugar and nucleotide sugar metabolism & mgr00520 & 1 & 41 & 0.610093064 & 22 \\
\hline RNA degradation & mgr03018 & 1 & 47 & 0.659457103 & 17 \\
\hline Protein processing in endoplasmic reticulum & mgr04141 & 1 & 74 & 0.815282306 & 16 \\
\hline Cell cycle - yeast & mgr04111 & 1 & 76 & 0.823495045 & 21 \\
\hline Ribosome & $\mathrm{mgr} 03010$ & 1 & 107 & 0.91304204 & 20 \\
\hline
\end{tabular}

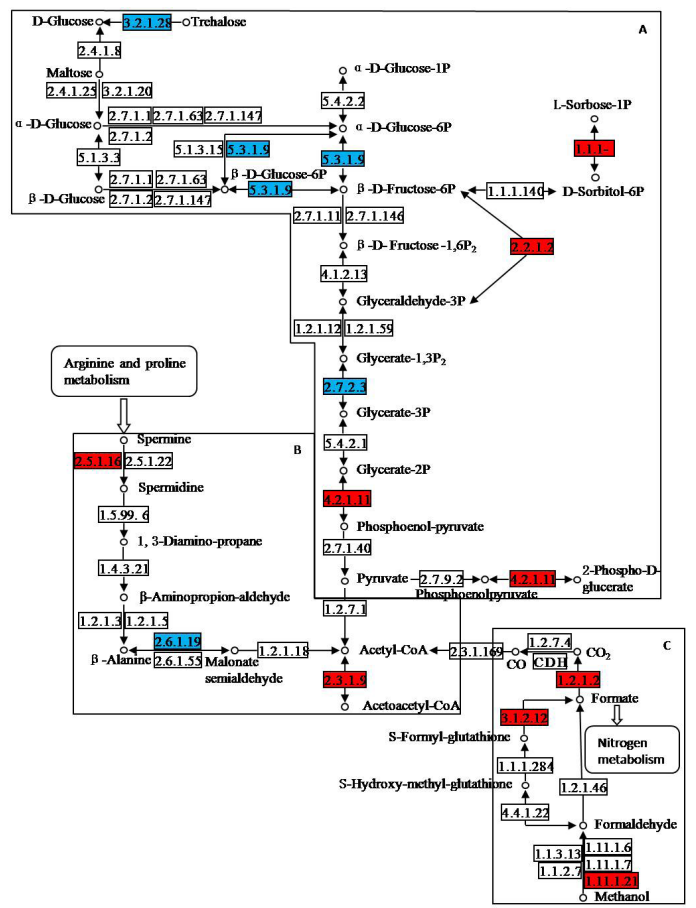

Figure 3. Images of differentially expressed proteins in KEGG pathway from Magnaporthe oryzae. Red boxes: up-regulated enzymes, blue boxes: down-regulated enzymes. 
deoxygenates glyceraldehyde to glycerol. Glycerol accumulation induces mycelium infection. Moreover, aldose reductase also plays a key role in inducing $\beta$-galactosidase and cellulose by lactose. However, cellulose, as a hydrolase of polysaccharides in the plant cell wall, plays an important role in pathogenic formation. Transaldolase and aldose reductase are up-regulated in the mycelium of $M$. oryzae under nitrogen starvation stress conditions, suggesting that $M$. oryzae manipulates nutrient metabolism and pathogenicity by regulating specific reactions of glucose metabolism during nitrogen starvation. As a multi-functional protein, enolase plays an important role in infection with various pathogens (Marcos et al., 2012). This enzyme was up-regulated under nitrogen starvation conditions, which may be related to pathogenicity. Formate dehydrogenase is widely used in NADH recycling. This enzyme oxidizes formic acid to $\mathrm{CO}_{2}$, while it reduces the coenzyme $\mathrm{NAD}^{+}$to $\mathrm{NADH}$. Production of this enzyme marks the start adaptive metabolic processes after $M$. oryzae mycelia are placed into rice internal structures. $S$-Formyl glutathione hydrolase is regulated by carbon and nitrogen source and is involved in the glutathione-dependent formaldehyde oxidation pathway. Its products can be used as carbon sources for growth (Yurimoto et al., 2003). Our results showed that the expression of $S$-formyl glutathione hydrolase in the mycelia was down-regulated under low nitrogen stress, suggesting that $M$. oryzae enhanced nitrogen metabolism in the mycelia and improved the synthetic ability of the desired carbon and nitrogen in order to ameliorate the adaptability of strains to adverse environmental conditions of nitrogen deficiency.

As a host barrier in the infection process, serine proteases function to degrade proteins and are pathogenic determinants. Subtilisin-like serine protease, a pathogenesis-related protein of M. oryzae, can regulate M. oryzae mycelial growth within the host cell. Dean et al. (2005) showed that the gene for serine protease in $M$. oryzae mycelia was more highly expressed under nitrogen stress conditions, indicating that this gene is associated with pathogenicity. Donofrio et al. (2006) suggested that the subtilase family of $M$. oryzae plays a key role in pathogenesis. Saitoh et al. (2009) showed that subtilisin-like serine protease, encoding gene SPM1 of M. oryzae, is closely related to the growth rate of mycelia, the ascus size of conidia, spore germination, and spore production. It is also a virulence-related gene that plays an important role in the autophagy process of $M$. oryzae infection. In the present study, we found that subtilisin-like serine protease was up-regulated, suggesting that nitrogen affects the expression of subtilisin-like serine protease in the mycelia to enhance disease resistance.

A variety of fungi can secrete oxalic acid during the pathogenic process, leading to hundreds of plant diseases and seriously impair crop production worldwide (Williams et al., 2011). Oxalic acid becomes calcium oxalates by chelating calcium in the cell wall to break the cell wall structure for pathogenic fungal invasion (Heller et al., 2013). Oxalate decarboxylase is an enzyme that can degrade oxalic acid to formic acid and $\mathrm{CO}_{2}$. Moreover, it can further alleviate fungal diseases to some extent. In this study, oxalate decarboxylase in the mycelia was down-regulated under nitrogen stress conditions, suggesting that $M$. oryzae regulates oxalate decarboxylase content to increase oxalic acid formation.

In the present study, we analyzed total mycelial proteins of $M$. oryzae under nitrogen stress conditions using 2-DE. A total of 23 up-regulated proteins and 20 down-regulated proteins were identified by MS. These proteins were primarily involved in development and metabolic processes of the pathogen. M. oryzae altered the process of growth and development of various physiological processes by regulating protein expression to adapt to nitrogen starvation stress and to improve resistance. In future studies, the morphology and pathogenicity of mycelia under nitrogen starvation stress should be investigated. Additionally, the expression of related 
proteins identified by proteomics should be verified at the mRNA level using real-time fluorescence quantitative polymerase chain reaction. Specific genes should be also screened to improve the understanding of their functions and underlying molecular pathways.

\section{Conflicts of interest}

The authors declared no conflict of interest.

\section{ACKNOWLEDGMENTS}

Research supported by the National Natural Science Foundation of China (\#31060021) and The Provincal Sci-Foundation of Yunnan (\#2006C0062M; \#2008ZC100M).

\section{REFERENCES}

Agrawal GK and Rakwal R (2011). Rice proteomics: A move toward expanded proteome coverage to comparative and functional proteomics uncovers the mysteries of rice and plant biology. Proteomics 11: 1630-1649. http://dx.doi. org/10.1002/pmic.201000696

Bhadauria V, Wang LX and Peng YL (2010). Proteomic changes associated with deletion of the Magnaporthe oryzae conidial morphology-regulating gene COM1. Biol. Direct 5: 1-19. http://dx.doi.org/10.1186/1745-6150-5-61

Bradford MM (1976). A rapid and sensitive method for the quantitation of microgram quantities of protein utilizing the principle of protein-dye binding. Anal. Biochem. 72: 248-254. http://dx.doi.org/10.1016/0003-2697(76)90527-3

Bregar O, Mandelc S, Celar F and Javornik B (2012). Proteome analysis of the plant pathogenic fungus Monilinia laxa showing host specificity. Food Technol. Biotechnol. 50: 326-333.

Cortina C and Culiáñez-Macià FA (2005). Tomato abiotic stress enhanced tolerance by trehalose biosynthesis. Plant Sci. 169: 75-82. http://dx.doi.org/10.1016/j.plantsci.2005.02.026

Dean RA, Talbot NJ, Ebbole DJ, Farman ML, et al. (2005). The genome sequence of the rice blast fungus Magnaporthe grisea. Nature 434: 980-986. http://dx.doi.org/10.1038/nature03449

Donofrio NM, Oh Y, Lundy R, Pan H, et al. (2006). Global gene expression during nitrogen starvation in the rice blast fungus, Magnaporthe grisea. Fungal Genet. Biol. 43: 605-617. http://dx.doi.org/10.1016/j.fgb.2006.03.005

Fernández-Acero FJ, Colby T, Harzen A, Carbú M, et al. (2010). 2-DE proteomic approach to the Botrytis cinerea secretome induced with different carbon sources and plant-based elicitors. Proteomics 10: 2270-2280. http://dx.doi. org/10.1002/pmic. 200900408

Garg AK, Kim JK, Owens TG, Ranwala AP, et al. (2002). Trehalose accumulation in rice plants confers high tolerance levels to different abiotic stresses. Proc. Natl. Acad. Sci. USA 99: 15898-15903. http://dx.doi.org/10.1073/ pnas. 252637799

Heller A and Witt-Geiges T (2013). Oxalic acid has an additional, detoxifying function in Sclerotinia sclerotiorum pathogenesis. PLoS One 8: e72292.

Jones OAH, Maguire ML, Griffin JL, Jung YH, et al. (2011). Using metabolic profiling to assess plant-pathogen interactions: an example using rice (Oryza sativa) and the blast pathogen Magnaporthe grisea. Eur. J. Plant Pathol. 129: 539-554. http://dx.doi.org/10.1007/s10658-010-9718-6

Liu J, Wang X, Mitchell T, Hu Y, et al. (2010). Recent progress and understanding of the molecular mechanisms of the rice-Magnaporthe oryzae interaction. Mol. Plant Pathol. 11: 419-427. http://dx.doi.org/10.1111/j.13643703.2009.00607.x

Mahajan S and Tuteja N (2005). Cold, salinity and drought stresses: an overview. Arch. Biochem. Biophys. 444: 139-158. http://dx.doi.org/10.1016/j.abb.2005.10.018

Marcos CM, de Fátima da Silva J, de Oliveira HC, Moraes da Silva RA, et al. (2012). Surface-expressed enolase contributes to the adhesion of Paracoccidioides brasiliensis to host cells. FEMS Yeast Res. 12: 557-570. http:// dx.doi.org/10.1111/j.1567-1364.2012.00806.x

Mathioni SM, Beló A, Rizzo CJ, Dean RA, et al. (2011). Transcriptome profiling of the rice blast fungus during invasive plant infection and in vitro stresses. BMC Genomics 12: 1-20. http://dx.doi.org/10.1186/1471-2164-12-49

Noir S, Colby T, Harzen A, Schmidt J, et al. (2009). A proteomic analysis of powdery mildew (Blumeria graminis f.sp. 
hordei) conidiospores. Mol. Plant Pathol. 10: 223-236. http://dx.doi.org/10.1111/j.1364-3703.2008.00524.x

Rathour R, Singh BM and Plaha P (2003). Nitrogen stress induces Magnaporthe grisea (Hebert) Barr to secrete protoplastdisrupting proteins. Indian J. Biotechnol. 2: 558-563.

Saitoh H, Fujisawa S, Ito A, Mitsuoka C, et al. (2009). SPM1 encoding a vacuole-localized protease is required for infection-related autophagy of the rice blast fungus Magnaporthe oryzae. FEMS Microbiol. Lett. 300: 115-121. http://dx.doi.org/10.1111/j.1574-6968.2009.01769.x

Salmerón-Santiago KG, Pardo JP, Flores-Herrera O, Mendoza-Hernández G, et al. (2011). Response to osmotic stress and temperature of the fungus Ustilago maydis. Arch. Microbiol. 193: 701-709. http://dx.doi.org/10.1007/s00203$\underline{011-0706-9}$

Talbot NJ (2003). On the trail of a cereal killer: Exploring the biology of Magnaporthe grisea. Annu. Rev. Microbiol. 57: 177-202. http://dx.doi.org/10.1146/annurev.micro.57.030502.090957

Wang Y, Wu J, Park ZY, Kim SG, et al. (2011). Comparative secretome investigation of Magnaporthe oryzae proteins responsive to nitrogen starvation. J. Proteome Res. 10: 3136-3148. http://dx.doi.org/10.1021/pr200202m

Williams B, Kabbage M, Kim HJ, Britt R, et al. (2011). Tipping the balance: Sclerotinia sclerotiorum secreted oxalic acid suppresses host defenses by manipulating the host redox environment. PLoS Pathog. 7: e1002107.

Yu P, Su Y, Dong C, Yao CX, et al. (2015). Preliminary proteomic analysis of tobacco leaves affected by volatile organic compounds from floral scent of rose. Plant Growth Regul. 75: 689-694. http://dx.doi.org/10.1007/s10725-014-9970-4

Yurimoto H, Lee B, Yano T, Sakai Y, et al. (2003). Physiological role of S-formylglutathione hydrolase in C(1) metabolism of the methylotrophic yeast Candida boidinii. Microbiology 149: 1971-1979. http://dx.doi.org/10.1099/mic.0.26320-0 